\title{
Cooperation Modes between Competing Manufacturers in EV Supply Chain with Innovation-Driven Common Supplier
}

\author{
Bin Liu $(\mathbb{D})$ and Ruoying Huang \\ Business School, University of Shanghai for Science and Technology, Shanghai 200093, China \\ Correspondence should be addressed to Bin Liu; liubhnau@163.com
}

Received 19 November 2021; Revised 5 January 2022; Accepted 29 January 2022; Published 16 February 2022

Academic Editor: Samuel Labi

Copyright (c) 2022 Bin Liu and Ruoying Huang. This is an open access article distributed under the Creative Commons Attribution License, which permits unrestricted use, distribution, and reproduction in any medium, provided the original work is properly cited.

\begin{abstract}
The competition and cooperation between automobile manufacturers and battery enterprises are an important topic concerned by electric vehicle supply chain management. This paper investigates the cooperation modes between competing manufacturers in the EV (electric vehicle) supply chain, under which the common supplier launches the innovation of the key component of EV to meet the demand of two manufacturers. Three cooperation modes between manufacturers, full cooperation, partial cooperation, and noncooperation, are established to depict the pricing decisions by the Stackelberg game. We find out that, when competition degree is small, it is more profitable to choose partial cooperation, while it is more advantageous to choose full cooperation when competition degree is high, and the manufacturer's basic market demand is relatively small. Therefore, it is always preferred for the common supplier to expect noncooperation between manufacturers. Under the background that basic market demand ratio changes with competition degree between markets, it could be better for the whole supply chain when without cooperation or partial cooperation depended on the supplier power while it could be better for customers when full cooperation or partial cooperation depended on the competition degree between manufacturers.
\end{abstract}

\section{Introduction}

Facing the great challenges of transportation energy and environmental problems, new energy vehicles characterized by energy diversification, clean emission, and fuel conservation are developing rapidly all over the world. At present, international auto giants have accelerated the promotion of electric vehicle strategy. Batteries, as the most important component of electric vehicles, become the focus of the competition among global automotive component suppliers, and all companies want to occupy a high position in the new energy vehicle market. In the electric vehicle battery market, not only do battery suppliers begin to carry out technological innovation but also automobile manufacturers are actively innovating. For example, a well-known battery supplier is striving for orders from global automobile manufacturers; on the other hand, some automobile manufacturers intend to master the core battery technology by themselves. For example, Tesla, the main customer of Panasonic batteries, plans to develop and produce the required batteries by itself.

In practice, there is usually a cooperative relationship between a common supplier and multiple competitive manufacturers. For example, Huawei and Xiaomi will jointly sign a contract on CPU (central processing unit) with Qualcomm Snapdragon, and BMW and Jaguar will use the same chassis supplier. In this case, the products of downstream competitive manufacturers will compete with each other in the market, but all manufacturers who sign a contract with a common supplier will have common benefits. How to decide the cooperation mode for competing manufacturers facing the common supplier is a problem worthy of attention. This paper studies this problem and provides some meaningful guidance for the operation and management of the supply chain. 
The rest of this paper is organized as follows: Section 2 presents the related literature, and section 3 discusses the research assumptions and basic models. Then, section 4 is three cooperation models between competing manufacturers, and their comparison and equilibrium analysis are in section 5. Finally, section 6 is the results and further research.

\section{Related Literature}

Innovation is always an important issue concerned by academia and industry. From the perspective of supply chain member innovation, this paper mainly focuses on two research fields. One research area includes supplier innovation in the supply chain, and supplier innovation can be divided into active innovation or buyer incentive supplier innovation. Sometimes, suppliers will take the initiative to improve product quality and technical level. Similarly, the buyer requires the supplier to meet the demand for product improvement. With the increase of global innovation outsourcing and the rising trend of open innovation, suppliers play a very important role in the global supply chain. In terms of supplier competition, Qi et al. [1] take a dualchannel supply chain composed of two upstream suppliers and one downstream manufacturer as the background. Considering the wholesale price factor, Qi et al. [1] analyze the optimal strategy for manufacturers to select suppliers when there is competition among suppliers. Li and Wan [2] investigate the impact of information asymmetry and information symmetry on supplier investment cost.

In the existing literature, supply chain competition is generally studied from three aspects: manufacturer competition, supplier competition, and considering the competition among multiple chains. For example, manufacturers tend to compete in terms of the product price, the service, and the quality. Xiang et al. [3] focus on the situation under which there is recycling competition in the process of remanufacturing waste products obtained by multiple manufacturers in the market, using optimization theory and noncooperative game theory, and discuss the impact of competition among remanufacturers and remanufacturing cost on the relationship between supply chain members. Zhu and Zhou [4] conduct research around the new energy vehicle industry related to the hot topic of government subsidies and analyze the competitive relationship between component manufacturers and remanufacturers by establishing a game model. Özdemir et al. [5] study the manufacturer's remanufacturing decision in the environment of a legislative disposal fee. Wu et al. [6] consider the competition between manufacturers and remanufacturers and investigate the manufacturer's strategic dilemma when determining the degree of disassembly. Subramanian et al. [7] extend the classic component commonality decision to consider remanufacturing operated by manufacturers or remanufacturers. The investment in component commonality can be regarded as an investment in reducing remanufacturing costs. Their analysis identifies the conditions under which generic decisions could be reversed by remanufacturing. $\mathrm{Li}$ et al. [8] investigate the impact of remanufacturing on product design, especially the quality of new products. They find that remanufacturing prompted monopolists to provide new products of higher quality.

Recent operations management literature studies issues surrounding the green technology innovation market (such as [9-14]), including environmental taxes and subsidies, policy issues, strategic decision-making, production decisions, and supply chain performance. In terms of research related to supply chain management innovation, $\mathrm{Li}$ and $\mathrm{Zhu}$ [15] depict the disadvantages of product positioning strategy and the advantages of product platform strategy when product innovation faces fierce competition and encourages managers to expand their ideas of technology $R \& D$ and product innovation. $\mathrm{Yu}$ and $\mathrm{Li}$ [16] probe into the optimal decision-making of channel members under different innovation strategies under the dominant and nondominant position of suppliers by establishing the product innovation model of suppliers and retailers. Huo et al. [17] find that product-oriented service transformation and incremental innovation have no significant complementary effect on the high-quality development of manufacturing enterprises, which is helpful to solve the problem of enterprise product innovation strategy selection. $\mathrm{Ni}$ and Zhao [18] establish a game theory model to find out the impact of vertical competition and cooperation on product innovation in the supply chain and compare the innovation investment level and the optimal decisions of upstream suppliers and downstream retailers under vertical competition and cooperation. Guoyin et al. [19] build an incomplete information dynamic game model between enterprises and consumers, investigate how enterprises motivate consumers through the innovation degree of new products, and decide whether to produce and sell products through the information fed back by consumers.

In the research field of alliance cooperation behavior in supply chain and operation management, Zhao et al. [20] investigate the collision behavior of two manufacturers in the retailer-led supply chain, and undoubtedly, manufacturers collude to make shelf space and pricing decisions to maximize their total profits. The cost difference is the key factor affecting their collusion decision-making, which will only pose an unreliable threat to retailers. Collusion is a nonprofit strategy, which involves the horizontal competition of manufacturers when there are large differences in costs. Melkonyan et al. [21] discuss the impact of collusion, which distinguishes the results between Bertrand and Cournot competition. They find out that virtual bargaining can make participants collude and obtain higher profits; in contrast, it does not make much sense in the Cournot competition. Chen et al. [22] study the problem of responsible procurement under the collusion of suppliers and auditors. An effective contract strategy is proposed to reduce collusion and eliminate the impact of screening errors and social efficiency loss caused by supplier audit collusion. In the aviation supply chain, there are also relevant studies on alliance cooperation [23-25], which mainly analyze the cooperation motivation between airlines and airports.

In addition, in the past few decades, there has been a lot of research on supply chain innovation. Wong and Ngai [26] 
believe that supply chain innovation is usually the stage of the supplier, manufacturer, and "supplier plus manufacturer." They propose that the innovation can be divided into three categories from the perspective of organizational behavior: market-oriented innovation activities, logistics-oriented innovation activities, and technology-based innovation activities. According to the definition of innovation, Gao et al. [27] propose six types of innovation, namely product innovation, process innovation, technological innovation, organizational innovation, marketing innovation, and resource allocation innovation. The above scholars have classified innovation from the macro level. In addition, Bruce [28] proposes that from the perspective of innovation-driven, the innovation can be divided into technology-driven innovation and market-driven innovation.

The product innovation activities considered in this paper are mainly based on the improvement of product quality level. By establishing the model, taking the product quality level and the service quality level of manufacturers and retailers into account in the supply chain, and studying the results under different game situations, it is concluded that the adjustment speed of the service quality level of manufacturers and retailers is too fast, which will eventually bring losses to the whole supply chain.

This paper will investigate how competitive manufacturers can negotiate with suppliers in the face of three different modes: full cooperation (manufacturers as an alliance, the same wholesale price, and the same sale prices), partial cooperation (unified wholesale price and different sale prices for manufacturers), and noncooperation (different wholesale prices and different sale prices), and whether the alliance between manufacturers can gain advantages in negotiations with suppliers. Furthermore, which operation mode preferred for suppliers is discussed.

\section{Research Assumptions and Basic Model}

This paper discusses a vehicle supply chain system consisting of the common supplier and competing manufacturers. Manufacturers have the same product types and compete in the product market (manufacturers have the same technology). From the perspective of the vertical structure of the supply chain, the supply chain structure of one supplier and two manufacturers allows the shared supplier to have a higher right to speak, and a single manufacturer is at a disadvantage when negotiating with it. So, at this time whether downstream manufacturers cooperate to enhance their bargaining power with suppliers, such as Ford and Jaguar Land Rover jointly invest in innovation in battery suppliers, while Tesla and Volkswagen are negotiating with Panasonic battery suppliers, respectively. Based on this, this paper studies the impact of three different interaction behaviors of manufacturers on the decision-making of supply chain members. The common suppliers take the initiative to innovate and provide competitive manufacturers with key components required for vehicle production. When manufacturers sign agreements and cooperate with suppliers, they can consider how to cope with their competitors. The cooperation modes between competing manufacturers can be divided into three ways, full cooperation, partial cooperation, and noncooperation. Full cooperation of manufacturers means that manufacturers form alliances in the downstream to determine the prices of products to be sold; partial cooperation means that manufacturers maximize their overall profits in the downstream market, but the products compete in the market they face; noncooperation means that manufacturers use their own profits. Maximize is the principle and compete in the product market.

In the supply chain composed of one supplier and two manufacturers, the supplier has a higher voice, and the negotiation with the manufacturer alliance will lose their position. It is worth considering whether downstream manufacturers cooperate to enhance their bargaining power with suppliers or negotiate with suppliers alone. This paper analyzes the impact of manufacturers' interactive behavior on supply chain members' decision-making. The idea for this part comes from the literature [29].

According to the decision-making order, the supplier first determines its wholesale price and innovation level, and the manufacturer determines its cooperation $\mathrm{V}$ mode and then determines the sales price. We call the manufacturer's full cooperation case $C$, partial cooperation case $S$, and noncooperation case $N$, respectively. We will build models for decision analysis. The following parameters will be used in this paper, and their meanings are shown in Table 1.

We assume that the manufacturers' basic demand is $A_{i}$ when $e=0$, where $e$ is the innovation level. If the common supplier determines its innovation level, the basic demand of the manufacturer $i$ becomes $a_{i}\left(a_{i}=A_{i}+e\right)$. Furthermore, the competition degree between markets is $\theta(\theta<1)$. We also assume that $C\left(e_{s}\right)=\varphi_{s} e_{s}^{2}$ alike literature $[30,31]$, and for simpler, the coefficient $\varphi_{s}=1$. Through numerical example analysis, these assumptions do not affect the results.

Referring to the market demand model of Ingene $[32,33]$, here, the market demand function and consumption utility function of manufacturer $i$ are as follows:

$$
\begin{gathered}
D_{i}=\frac{a_{i}-\theta * a_{3-i}-p_{i}+\theta * p_{3-i}}{1-\theta^{2}}, \quad(i=1,2), \\
U \equiv \sum_{i=1,2}\left(\alpha_{i} D_{i}-\frac{D_{i}^{2}}{2}\right)-\theta D_{1} D_{2}-\sum_{i=1,2} p_{i} D_{i} .
\end{gathered}
$$

To express the potential asymmetry between the markets confronted by two chains, here, we define $\Omega \equiv A_{1} / A_{2}$. We also refer to $\Omega$ as the base demand ratio. If $\Omega>1$, the chain 1 's initial base demand is larger than that of chain 2's. This has been discussed in it [34].

\section{Cooperation Models between Manufacturers: Three Cooperation Scenarios}

4.1. Scenarios C: Full Cooperation between Manufacturers. Under the scenario of full cooperation between manufacturers, the supplier gives the same wholesale price to two manufacturers. The manufacturers ally with the downstream 
TABle 1: Definitions of model parameters.

\begin{tabular}{lc}
\hline Parameters & Definition \\
\hline$A_{i}$ & Basic demand in the market $i, i=1,2$ \\
$a_{i}$ & Basic demand in market $i$ when $e \neq 0$ 时, $a_{i}=A_{i}+e ; i=1,2$ \\
$\Omega$ & Basic market demand ratio, $\Omega=A_{1} / A_{2}$ \\
$\eta$ & Supplier innovation level \\
$D_{i}$ & Manufacturer's share of innovation cost \\
$\theta$ & Demand in the market $i, i=1,2$ \\
$U$ & Competition degree between markets \\
$w$ & Consumer utility \\
$p_{i}$ & Wholesale price per unit \\
$C\left(e_{s}\right)$ & Selling price of manufacturer $i$ per unit, $i=1,2$ \\
$\pi_{m i}$ & Supplier innovation costs \\
$\pi_{s}$ & Profit of manufacturer $i, i=1,2$ \\
\hline
\end{tabular}

to determine the price of products. Taking this scenario as the benchmark, the decision-making order of both parties under this scenario is the supplier actively carries out upstream innovation and determines the innovation level and wholesale price; after learning that the supplier is innovating, the manufacturer chooses to fully cooperate in the sales of the final product and determine the price of the product. The demand function is

$$
D_{i}^{C}=\frac{\left(\alpha_{i}-\theta * \alpha_{3-i}-p^{C}+\theta * p^{C}\right)}{\left(1-\theta^{2}\right)} .
$$

The profit functions of suppliers and manufacturers are

$$
\begin{aligned}
\pi_{S}^{C} & =w^{C} *\left(D_{2}^{C}+D_{2}^{C}\right)-e_{1}^{2}, \\
\pi_{m 1}^{C} & =D_{1}^{C} *\left(p^{C}-w^{C}\right), \\
\pi_{m 2}^{C} & =D_{2}^{C} *\left(p^{C}-w^{C}\right) .
\end{aligned}
$$

Taking the reverse order solution method, the manufacturer's profit function is a concave function on price $p$. When the manufacturer fully cooperates, the two strategic alliance manufacturers determine the product price $p$ based on the principle of maximizing their overall profit. We can get the selling price $p^{C}=1 / 4\left(A_{1}+A_{2}+2\left(w^{C}+e_{1}\right)\right)$ given the wholesale price $w^{C}$. And then, to substitute $p^{C}$ into formula (3), we can get the profit of supplier $\pi_{s}^{C}=w^{C}\left(A_{1}+A_{2}-2 w^{C}\right)+2 w^{C} e_{1}-2(1+\theta) e_{1}^{2} / 2(1+\theta)$.

By the same method, we can prove the profit of supplier, $\pi_{s}$, is joint concave on $(w, e)$. So, we can get the optimal wholesale price and innovation level, respectively, $w^{C^{*}}=(1+\theta)\left(A_{1}+\right.$ $\left.A_{2}\right) / 3+4 \theta$ and $e_{1}^{*}=A_{1}+A_{2} / 6+8 \theta$ according to the firstorder necessary condition of $\pi_{s}$. Furthermore, we can get the optimal selling price $p^{C^{*}}=3(1+\theta)\left(A_{1}+A_{2}\right) / 6+8 \theta$ and then gain the optimal profits of all members and the whole supply chain as follows:

$$
\begin{aligned}
& \pi_{m 1}^{C^{*}}=\frac{(1+\theta)\left(A_{1}+A_{2}\right)\left((4+3 \theta) A_{1}-(2+5 \theta) A_{2}\right)}{4(1-\theta)(3+4 \theta)^{2}}, \\
& \pi_{m 2}^{C^{*}}=\frac{(1+\theta)\left(A_{1}+A_{2}\right)\left((4+3 \theta) A_{2}-(2+5 \theta) A_{1}\right)}{4(1-\theta)(3+4 \theta)^{2}}, \\
& \pi_{s}^{C^{*}}=\frac{\left(A_{1}+A_{2}\right)^{2}}{4(3+4 \theta)} .
\end{aligned}
$$

4.2. Scenarios S: Partial Cooperation between Manufacturers. In the manufacturer's partial cooperative scenario, although the supplier will adopt a unified wholesale price, the manufacturer will set their product prices based on the principle of maximizing their profits and compete with their products in the market, such as Ford and Jaguar Land Rover. The decision-making order of both parties is that the supplier actively carries out upstream innovation and determines the innovation level and wholesale price. After learning that the supplier carries out innovation, the manufacturer chooses partial cooperation to sell the final products and determine the price of its products, respectively. Here, the demand function is

$$
D_{i}^{S}=\frac{\alpha_{i}-\theta * \alpha_{3-i}-p_{i}^{S}+\theta * p_{3-i}^{S}}{1-\theta^{2}} .
$$

The profit functions of supplier and manufacturers are

$$
\begin{aligned}
\pi_{s}^{S} & =w^{S} *\left(D_{1}^{S}+D_{2}^{S}\right)-e_{2}^{2}, \\
\pi_{m 1}^{S} & =D_{1}^{S} *\left(p_{1}^{S}-w^{S}\right), \\
\pi_{m 2}^{S} & =D_{2}^{S} *\left(p_{2}^{S}-w^{S}\right) .
\end{aligned}
$$

By the same method, we can prove the supplier's profit function $\pi_{s}^{S}$ is joint concave on $\left(w^{S}, e_{2}\right)$. So, we can get the 
optimal wholesale price and innovation level $w^{S^{*}}=(2-\theta)(1+\theta)\left(A_{1}+A_{2}\right) / 6+4(1-\theta) \theta \quad$ and $e_{2}^{*}=A_{1}+A_{2} / 6+4(1-\theta) \theta$. And then, the optimal selling prices are $p_{1}^{S^{*}}=(1+\theta)((9+\theta(1-4 \theta))$ $\left.A_{1}+3(1-\theta) A_{2}\right) / 2(2+\theta)(3+2(1-\theta) \theta) \quad$ and $p_{2}^{S^{*}}=(1+\theta)\left((9+\theta \quad(1-4 \theta)) A_{1}+3(1-\theta) A_{1}\right) / \quad 2(2+\theta)$ $(3+2(1-\theta) \theta)$.

The optimal profits of all members and the whole supply chain are as follows:

$$
\begin{aligned}
& \pi_{m 1}^{S^{*}}=\frac{(1+\theta)\left((5+\theta(1-3 \theta)) A_{1}-(1+(3-\theta) \theta) A_{2}\right)^{2}}{4(1-\theta)(2+\theta)^{2}(3+2(1-\theta) \theta)^{2}}, \\
& \pi_{m 2}^{S^{*}}=\frac{(1+\theta)\left(\left(5+\theta-3 \theta^{2}\right) A_{2}-(1+(3-\theta) \theta) A_{1}\right)^{2}}{4(1-\theta)(2+\theta)^{2}(3+2(1-\theta) \theta)^{2}} \\
& \pi_{s}^{S^{*}}=\frac{\left(A_{1}+A_{2}\right)^{2}}{12+8(1-\theta) \theta} .
\end{aligned}
$$

4.3. Scenarios N: Noncooperation between Manufacturers. Under the manufacturer's noncooperation scenario, the common supplier and manufacturers compete in the product market based on the principle of maximizing their respective profits, such as Xiaomi and Huawei. The decisionmaking order of both parties is that the supplier actively carries out upstream innovation and determines the innovation level and the wholesale price to different manufacturers, and the manufacturers choose not to cooperate after learning that the supplier carries out innovation, sells the final products, and determines the price of their products, respectively. Here, the demand function is

$$
D_{i}^{N}=\frac{\alpha_{i}-\theta^{*} \alpha_{3-i}-p_{i}^{N}+\theta^{*} p_{3-i}^{N}}{1-\theta^{2}} .
$$

The profit functions of the common supplier and manufacturers are listed as follows:

$$
\begin{aligned}
\pi_{s}^{N} & =w_{1}^{N} * D_{1}^{N}+w_{2}^{N} * D_{2}^{N}-e_{3}^{2}, \\
\pi_{m 1}^{N} & =D_{1}^{N} *\left(p_{1}^{N}-w_{1}^{N}\right), \\
\pi_{m 2}^{N} & =D_{2}^{N} *\left(p_{2}^{N}-w_{2}^{N}\right) .
\end{aligned}
$$

By the similar method, we can prove the common supplier's profit function $\pi_{s}^{N}$ is joint concave on $\left(w_{1}^{N}, w_{2}^{N}, e_{3}\right)$ by the third-order Hessian matrix analysis. Then, we can gain the optimal wholesale price and innovation level are $w_{1}^{N^{*}}=(7+4(1-\theta)) \theta A_{1}+A_{2} / 12$ $+8(1-\theta) \theta, w_{2}^{N *}=A_{1}+(7+4(1-\theta) \theta) A_{2} / 12+8(1-\theta) \theta$, and $e_{3}^{*}=A_{1}+A_{2} / 6+4(1-\theta) \theta$. Furthermore, the optimal selling prices of production in markets are as follows: $p_{1}{ }^{* *}=$ $(21+2 \theta(11-4 \theta(1+\theta))) A_{1}+\left(3-2 \theta-4 \theta^{2}\right) A_{2} / 4 \quad(2+\theta)$ $(3+2(1-\theta) \theta)$ and $p_{2}{ }^{N *}=(21+2 \theta(11-4 \theta \quad(1+\theta)$ )) $A_{2}+\left(3-2 \theta-4 \theta^{2}\right) A_{1} / 4(2+\theta)(3+2(1+\theta) \theta)$.

The optimal profits of all members and the whole supply chain are as follows:

$$
\begin{aligned}
& \pi_{m 1}^{N^{*}}=\frac{(1+\theta)\left(\left(7-4 \theta^{2}\right) A_{1}+(1-4 \theta) A_{2}\right)^{2}}{16(1-\theta)(2+\theta)^{2}(3+2(1-\theta) \theta)^{2}}, \\
& \pi_{m 2}^{N^{*}}=\frac{(1+\theta)\left(\left(7-4 \theta^{2}\right) A_{1}+(1-4 \theta) A_{1}\right)^{2}}{16(1-\theta)(2+\theta)^{2}(3+2(1-\theta) \theta)^{2}}, \\
& \pi_{s}^{N^{*}}=\frac{\left(7-4 \theta^{2}\right) A_{1}^{2}+2(1-4 \theta) A_{1} A_{2}+\left(7-4 \theta^{2}\right) A_{2}^{2}}{8\left(6+\theta-9 \theta^{2}+2 \theta^{4}\right)} .
\end{aligned}
$$

\section{Models Comparison and Equilibrium Analysis}

By solving the models of full cooperation, partial cooperation, and noncooperation, the optimal decisions and maximum profits of manufacturers and suppliers under different scenarios are obtained. This section will compare and analyze the maximum profit under three different scenarios to get relevant conclusions.

Proposition 1. Given innovation by the common supplier, for manufacturer 1's profit under three scenarios, we can get the following.

(1) Full cooperation is preferred for manufacturer 1 under the feasible zone, $\widehat{\Omega}_{m 1}^{C-S}<\Omega<\bar{\Omega}^{C}$ due to $\pi_{m 1}^{C}$ $>\pi_{m 1}^{S}>\pi_{m 1}^{N}$

(2) Partial cooperation is preferred for manufacturer 1 under the zone $\widehat{\Omega}_{m 1}^{C-N}<\Omega<\bar{\Omega}^{C}$ and $\widehat{\Omega}_{m 1}^{C-S}<\Omega<\bar{\Omega}^{C}$ due to $\pi_{m 1}^{S}>\pi_{m 1}^{C}>\pi_{m 1}^{N}$

(3) Noncooperation is preferred for manufacture 1 under $\underline{\Omega}^{C}<\Omega<\widehat{\Omega}_{m 1}^{C-N}$ due to $\pi_{m 1}^{N}>\pi_{m 1}^{S}>\pi_{m 1}^{C}$

From Proposition 1, we can find out that for manufacturers, when their basic market demand is close to their competitors and their products are highly competitive, manufacturers will choose full cooperation, which can form a strategic alliance and reduce the losses caused by competition; when the products of two manufacturers are less competitive in the market, as long as the basic market demand of the manufacturer is greater than that of the competitor, it will choose partial cooperation. At this time, it has a certain voice in the market, so choosing partial cooperation to set its product sales price alone is conducive to obtaining more profits from the market; when its basic market demand is relatively small compared with its competitors, regardless of the degree of market competition of products, it will choose not to cooperate and sign a separate contract with suppliers to ensure its voice in negotiation with suppliers, so that it can obtain more profits. Figure 1 illustrates the above results.

Proposition 2. Given innovation by the common supplier, for manufacturer 2's profit under three scenarios, we can get the following.

(1) Full cooperation is preferred for manufacturer 2 under the feasible zone, $\underline{\Omega}^{C}<\Omega<\widehat{\Omega}_{m 2}^{C-S}$ due to $\pi_{m 2}^{C}$ $>\pi_{m 2}^{S}>\pi_{m 2}^{N}$ 


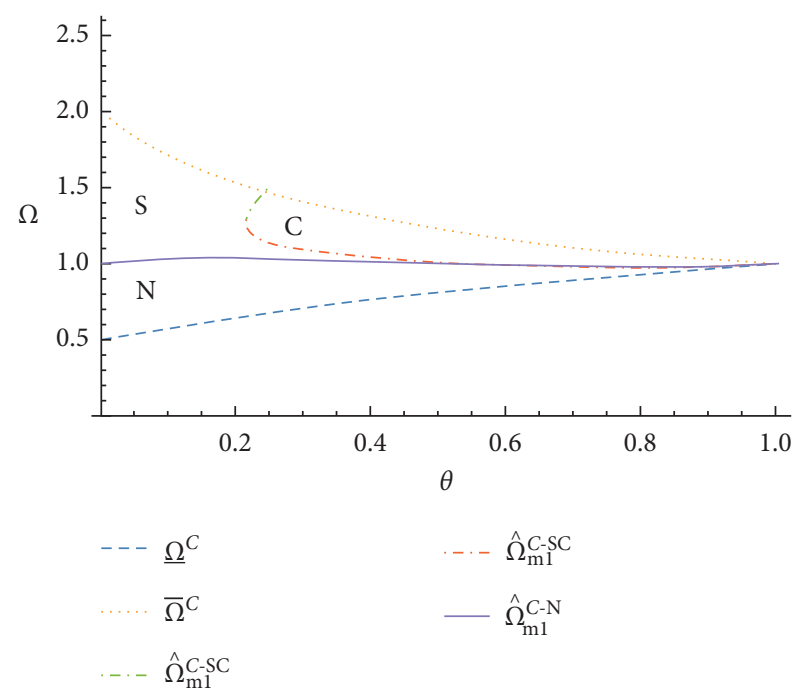

FIgURE 1: Cooperation mode choice for manufacturer 1 .

(2) Partial cooperation is preferred for manufacturer 2 under the zone $\underline{\Omega}^{C}<\Omega<\widehat{\Omega}_{m 2}^{C-N} \quad$ and
$\widehat{\Omega}_{m 2}^{C-S}<\Omega<\widehat{\Omega}_{m 2}^{C-N}$ due to $\pi_{m 2}^{S C}>\pi_{m 2}^{C}>\pi_{m 2}^{N}$

(3) Noncooperation is preferred for manufacture 2 under the zone $\widehat{\Omega}_{m 2}^{C-N}<\Omega<\bar{\Omega}^{C}$ due to $\pi_{m 2}^{N}>\pi_{m 2}^{S}>\pi_{m 2}^{C}$

From Proposition 2, it can be seen that for manufacturers, when their basic market demand is close to that of their competitors, and their products have high substitutability in the market; that is, there is great competition, and manufacturers will choose full cooperation, which can form a strategic alliance and reduce the losses caused by competition. In this case, the manufacturer and the competitor will reach an agreement to form a strategic alliance to sign a contract with the supplier; when the substitutability of two manufacturers' products is low in the market, that is, the competition is very small. As long as its basic market demand is greater than that of the manufacturer, it will choose partial cooperation. At this time, it has a certain voice in the market. Therefore, choosing partial cooperation to set its own product sales price alone is conducive to obtaining more profits from the market. When its basic market demand is relatively small compared with that of the manufacturer, no matter whether the product is more or less substitutable in the market; that is, competition degree is large or small, and it will choose noncooperation to sign a contract with the supplier alone, so as to ensure its voice in negotiation with the supplier and ensure that it can obtain more profits. Figure 2 illustrates the above results, and it is easy to find that Figure 2 is symmetrical with Figure 1.

From Propositions 1 and 2, we can get the following inference.

Inference 1. For the manufacturers, it is preferred to choose full cooperation with the common supplier if the basic market demand of two manufacturers is similar, and their products are highly competitive, while to choose noncooperation if there is an obvious gap between the basic market

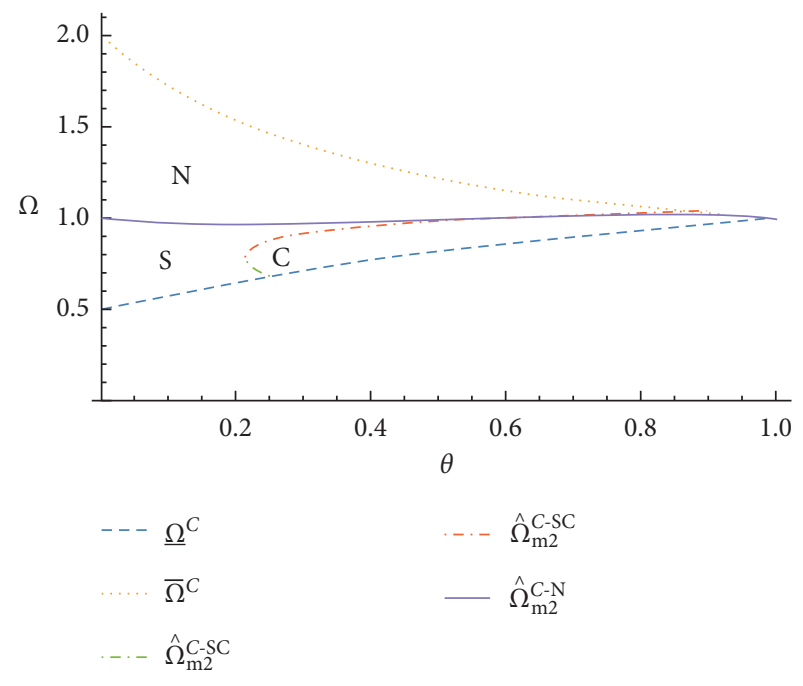

Figure 2: Cooperation mode choice for manufacture 2.

demand of the two manufacturers and competition degree is low.

Inference 1 implies that only two equilibriums occur, and partial cooperation will not be chosen because when their basic market demand is low, choosing partial cooperation will only be beneficial to competitors, so they will not choose partial cooperation mode.

Proposition 3. Facing the manufacturers' choice, the common supplier's innovation level $e_{3}>e_{2}=e_{1}$, and it is preferred to choose noncooperation under the zone $\underline{\Omega}^{C}<\Omega<\bar{\Omega}^{C}$ due to $\pi_{S}^{N}>\pi_{S}^{S}>\pi_{S}^{C}$.

From Proposition 3, we can find that for the common supplier, the innovation level is the same under the scenarios of full cooperation and partial cooperation with manufacturers; that is, when the manufacturer obtains products at the same wholesale price, it will choose the same innovation level to reduce the innovation cost; when the manufacturer does not cooperate, the wholesale price is different. Under the competition of the manufacturer, the supplier is willing to improve the innovation level and improve the competitiveness of the product, to obtain more profits. Figure 3 illustrates the above results well.

Proposition 4. For the whole supply chain, noncooperation is preferred under the zone $\widehat{\Omega}^{S-N}<\Omega<\bar{\Omega}^{C}$ due to $\pi^{N}>\pi^{S}>\pi^{C}$, while partial cooperation is preferred under the zone $\underline{\Omega}^{C}<\Omega<\widehat{\Omega}^{S-N}$ due to $\pi^{S}>\pi^{N}>\pi^{C}$.

From Proposition 4, we can find that for the whole supply chain, manufacturers will not choose to cooperate completely. This is because, under full cooperation, manufacturers are strategic alliances in downstream. When facing the market, the sales price is the same, and there is no motivation to strive for more profits. At this time, the innovation level of suppliers facing the downstream strategic alliance will also be reduced, which makes the overall profit the lowest; when the basic market demand of the whole supply chain is small, the manufacturer's partial cooperation strategy will be selected. At this time, for the whole supply chain, it needs to expand the 


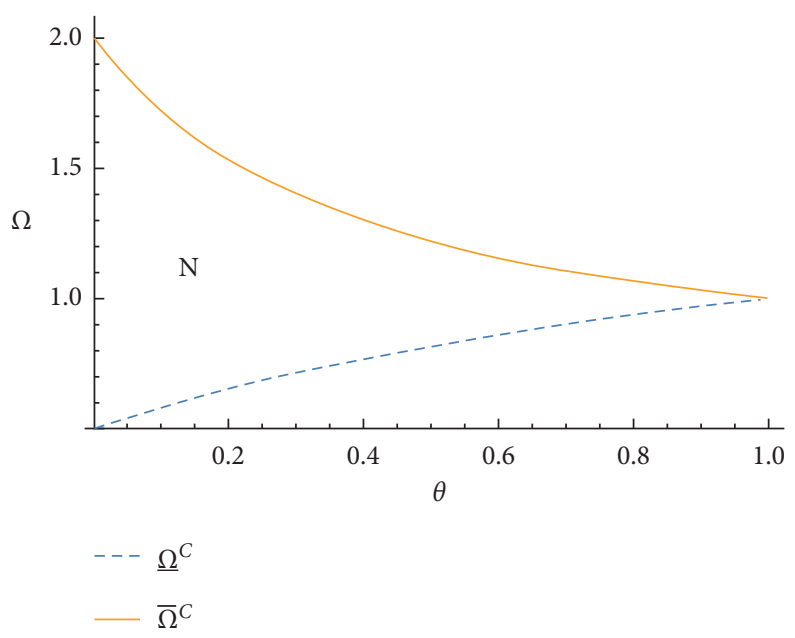

Figure 3: Cooperation mode choice for the common supplier.

basic market demand to improve the product sales to obtain more revenue. Therefore, the downstream manufacturers should avoid the loss of overall profits caused by complete competition; when the basic market demand of the whole supply chain is large, manufacturers will choose noncooperation. At this time, products have been recognized by consumers in the market, so manufacturers need to make more efforts through competition to make the market demand larger. When manufacturers compete, suppliers will also have more power to improve the innovation level and to make the whole supply chain obtain more profits. Figure 4 illustrates the above results well.

Proposition 5. For the consumers, partial cooperation is preferred under the zone $\underline{\Omega}_{U}^{C-N}<\Omega<\bar{\Omega}_{U}^{C-N}$ and $\underline{\Omega}^{C}<\Omega<\bar{\Omega}$ due to $U^{S}>U^{N}>U^{C}$, while full cooperation is preferred under the zone $\bar{\Omega}_{U}^{C-N}<\Omega<\bar{\Omega}^{C}$ 且 $\underline{\Omega}^{C}<\Omega<\underline{\Omega}_{U}^{C-N}$ due to $U^{C}>U^{S}>U^{N}$.

From Proposition 5, we can find that for consumers, when the basic market demand of two manufacturers is not much different, that is, the market share of their products is basically the same, and they will choose the manufacturer's partial cooperative scenario. At this time, there is both cooperation and competition between manufacturers to maximize the utility of consumers, and consumers will get more benefits; when there is a large difference between the basic market demand of two manufacturers, that is, one manufacturer's products occupy most of the consumer market, while the other manufacturer's products only occupy a small part of the consumer market, and the manufacturer with a large consumer market has more voice, which will be accepted by consumers even if the price is high. Therefore, for consumers, they prefer manufacturers to balance market prices through full cooperation to maximize their utility. Figure 5 illustrates the above results well.

\section{Results and Comments}

This paper constructs a supply chain system consisting of one common supplier and two manufacturers and investigates the manufacturer's selection strategies for three different scenarios of full cooperation, partial cooperation, and noncooperation in the competition setting. Simultaneously, the common supplier launches the innovation and obtains the decision-making of each member of the supply chain when the manufacturer selects different scenarios. By comparing the above models, we can find out the following results.

When manufacturers have a large demand in the basic market, to encourage suppliers to improve their innovation level, manufacturers should choose not to cooperate to strive for higher profits, so that suppliers and manufacturers can obtain the maximum benefits, respectively. From the perspective of consumer utility, for the supply chain, if the consumer utility is small, that is, the supply chain will get more profits from the market. Therefore, when the overall demand of products in the basic market is small, the manufacturer should choose full cooperation, and when the overall demand of the basic market is large, the manufacturer should choose noncooperation, to obtain more profits from consumers. For manufacturers, the discussion can be divided into two situations: the first is that the manufacturer's basic market demand is greater. When the competition degree is small, it is more profitable to choose partial cooperation. When competition degree is high, it is more advantageous to choose full cooperation; the second is that the manufacturer's basic market demand is relatively small. At this time, no matter how competition degree changes, choosing noncooperation is the optimal decision. Furthermore, enterprises should also realize that when they are in an advantageous position in the market, choosing not to cooperate is not necessarily beneficial. On the contrary, they should cooperate with other manufacturers in the market to improve their bargaining power and reduce the cost of obtaining products from suppliers to obtain more profits. Cooperation in competition and competitiveness in cooperation are the guarantee for the long-term development of enterprises. For example, in the electric vehicle market, electric vehicle manufacturers 


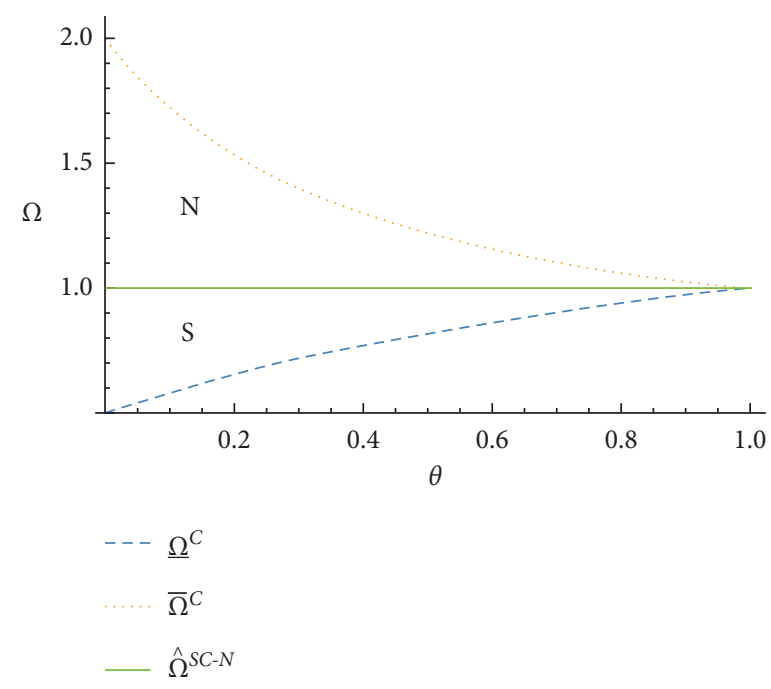

FIgURE 4: Performance of whole supply chain.

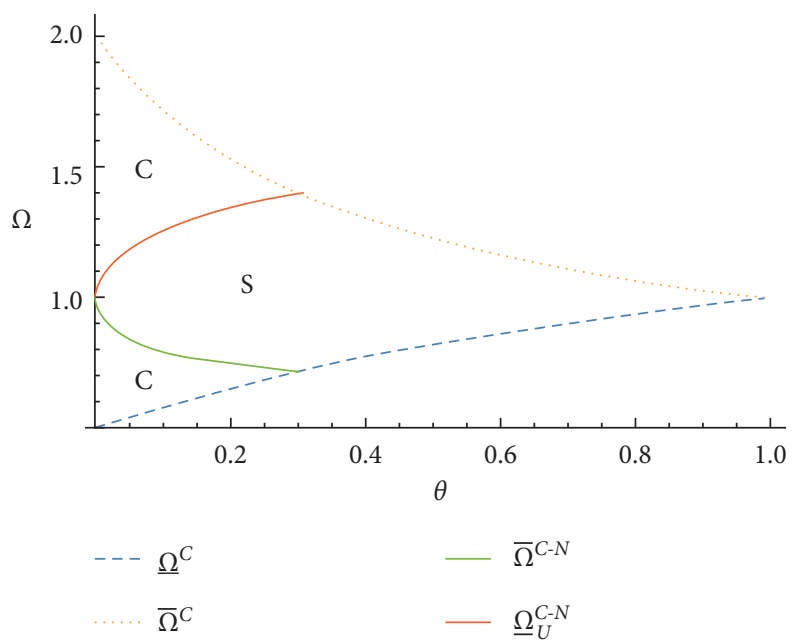

FIgURE 5: Cooperation preference of consumers.

choose more cooperative behavior to negotiate with suppliers.

At present, the epidemic is still spreading. As a huge supply chain system, any accident in the automobile industry may bring the impact of shutdown or delay in one link of the super long industrial chain, resulting in a chain reaction upstream and downstream of the whole industrial chain. In the supply chain of parts processing and manufacturing, when a supplier closes, other assembly factories that rely on the parts will also suffer heavy losses. Moreover, some parts are not replaceable, and the increase of uncertainty of upstream suppliers leads to the reduction of vehicle assembly output. This kind of "Domino" chain reaction leads to severe risks in the automobile supply chain. In the long run, it is difficult to judge the impact of the epidemic situation and the disruption of the operation rhythm of the industry. Industry insiders believe that the sales side will gradually recover only when the epidemic is controlled, but overall, the sales volume of the car market will be further reduced this year. However, in the face of the epidemic, we can neither ignore the complexity of the global economy nor underestimate its resilience. In extraordinary times, new business models will be promoted or strengthened. The new model, coupled with the huge market volume, means new industrial possibilities. Different from the past, the epidemic situation makes people clearly realize that the only way to ensure human survival is to follow the objective laws of nature and realize the harmonious coexistence between man and nature. Therefore, it is very important to realize the "ecology" of automobile driving and pay more attention to the purification of air in the vehicle and the development of anti-virus, disinfection, and other functions, so as to better protect the safety and health of drivers and passengers, which has become a new direction of automobile technology $\mathrm{R} \& \mathrm{D}$ and innovation in the future.

From the perspective of manufacturers' own market demand, this paper analyzes the influence of different interactions between manufacturers on the decision-making of 
the supply chain and its members, and the conclusions drawn are inspiring for electric vehicle manufacturers. But this article only considers the scenario when downstream manufacturers have the same technology and does not consider other scenarios, such as the competition situation or when downstream manufacturers have different technologies. In addition, it has not considered whether the decision-making results of supply chain members will change when downstream manufacturers provide cost sharing to the supplier. This scenario can be used as a followup research direction.

\section{Data Availability}

The data used to support the findings of this study are included within the article.

\section{Conflicts of Interest}

The authors declare that they have no conflicts of interest.

\section{Acknowledgments}

This work was supported by the National Science Foundation of China with Grant number No. 71971134 hosted by Dr. and Professor Liu Bin.

\section{References}

[1] A. Qi, H.-S. Ahn, and A. Sinha, "Investing in a shared supplier in a competitive market: Stochastic capacity case," Production and Operations Management, vol. 24, no. 10, pp. 1537-1551, 2015.

[2] C. Li and Z. Wan, "Supplier competition and cost improvement," Management Science, vol. 63, no. 8, pp. 24602477, 2016.

[3] L. Xiang and Y. Li, "Multi remanufacturing recycling pricing competition game," Journal of Management in Engineering, vol. 26, no. 2, pp. 72-76, 2012.

[4] Q. Zhu and S. Zhou, "Competitive analysis of auto parts manufacturers and remanufacturers based on government price subsidies," Journal of Systems Management, vol. 23, no. 3, pp. 367-373, 2014.

[5] Ö. Özdemir, M. Denizel, and V. D. R. Guide, "Recovery decisions of a producer in a legislative disposal fee environment," European Journal of Operational ReSearch, vol. 216, no. 2, pp. 293-300, 2012.

[6] C.-H. Wu, "Product-design and pricing strategies with remanufacturing," European Journal of Operational Research, vol. 222, no. 2, pp. 204-215, 2012.

[7] R. Subramanian, M. E. Ferguson, and L. Beril Toktay, "Remanufacturing and the component commonality decision," Production and Operations Management, vol. 22, no. 1, pp. 36-53, 2013.

[8] G. Li, M. Reimann, and W. Zhang, "When remanufacturing meets product quality improvement: The impact of production cost," European Journal of Operational Research, vol. 271, no. 3, pp. 913-925, 2018.

[9] H.-Y. Mak, Y. Rong, and Z.-J. M. Shen, "Infrastructure planning for electric vehicles with battery swapping," Management Science, vol. 59, no. 7, pp. 1557-1575, 2013.
[10] B. Avci, K. Girotra, and S. Netessine, "Electric vehicles with a batter switching station: Adoption and environmental impact," Management Science, vol. 61, no. 4, pp. 772-794, 2014.

[11] M. K. Lim, H. Mak, and Y. Rong, "Toward mass adoption of electric vehicles: Impacts of the range and resale anxieties," Manufacturing \& Service Operations Management, vol. 17, no. 1, pp. 101-119, 2014.

[12] S. P. Holland, E. T. Mansur, N. Z. Muller, and A. J. Yates, "Environmental benefits from driving electric vehicles?" National Bureau of Economic Research, https://www.nber.org/ papers/w21291, 2015.

[13] R. Miao, W. Huang, D. Pei et al., "Research on lease and sale of electric vehicles based on value engineering," International Journal of Production Research, vol. 54, no. 18, pp. 5361-5380, 2016.

[14] M. A. Javid, N. Ali, M. Abdullah, T. Campisi, and S. A. H. Shah, “Travelers' adoption behavior towards electric vehicles in lahore, Pakistan: an extension of norm activation model (NAM) theory," Journal of Advanced Transportation, vol. 2021, Article ID 7189411, 2021.

[15] G. Li and X. Zhu, "On the strategic transformation of enterprise technology R\&D and product innovation," Journal of Sichuan University, vol. 2, pp. 181-192, 2021.

[16] H. Yu and Y. Li, "Supplier's choice of product innovation strategy from the perspective of supply chain: financing vs non financing," Journal of Management in Engineering, vol. 3, pp. 1-9, 2021.

[17] C. Huo, X. Lv, and Y. Gong, "Research on the complementary effect of service transformation and product innovation on the high-quality development of manufacturing enterprises," Journal of Guangdong Finance and Economics University, vol. 36, no. 1, pp. 73-84, 2021.

[18] J. Ni and J. Zhao, "A dynamic analysis of the investment in product innovation in a supply chain under reference price effect: Competition vs cooperation," International Journal of Systems Science: Operations \& Logistics, vol. 8, no. 1, pp. 56-68, 2021.

[19] Z. Guoyin, D. Ni, and X. Tang, "Enterprise innovation capability, consumer participation and new product development," Journal of Management in Engineering, vol. 18, no. 2, pp. 253-261, 2021.

[20] J. Zhao, Y.-W. Zhou, Z.-H. Cao, and J. Min, "The shelf space and pricing strategies for a retailer-dominated supply chain with consignment based revenue sharing contracts," European Journal of Operational Research, vol. 280, no. 3, pp. 926-939, 2020.

[21] T. Melkonyan, H. Zeitoun, and N. Chater, "Collusion in Bertrand vs. Cournot competition: A virtual bargaining approach," Management Science, vol. 64, no. 12, pp. 5599-5609, 2018.

[22] L. Chen, S. Yao, and K. Zhu, "Responsible sourcing under supplier-auditor collusion," Manufacturing \& Service Operations Management, vol. 22, no. 6, pp. 1234-1250, 2020.

[23] C. Barbot, "Airport and airlines competition: incentives for vertical collusion," Transportation Research Part B: Methodological, vol. 43, no. 10, pp. 952-965, 2009.

[24] T. D'Alfonso and A. Nastasi, "Vertical relations in the air transport industry: A facility-rivalry game," Transportation Research Part E: Logistics and Transportation Review, vol. 48, no. 5, pp. 993-1008, 2012.

[25] C. Barbot, T. D'Alfonso, P. Malighetti, and R. Redondi, "Vertical collusion between airports and airlines: An empirical test for the European case," Transportation Research 
Part E: Logistics and Transportation Review, vol. 57, no. 1, pp. 3-15, 2013.

[26] D. T. W. Wong and E. W. T. Ngai, "Critical review of supply chain innovation research (1999-2016)," Industrial Marketing Management, vol. 82, pp. 158-187, 2019.

[27] D. Gao, Z. Xu, Y. Z. Ruan, and H. Lu, "From a systematic literature review to integrated definition for sustainable supply chain innovation (SSCI)," Journal of Cleaner Production, vol. 142, pp. 1518-1538, 2017.

[28] M. Bruce, "Dangerous liaisons: an application of supply chain modelling for studying innovation within the UK clothing industry," Technology Analysis \& Strategic Management, vol. 11, no. 1, pp. 113-125, 1999.

[29] C. Liu, W. Huang, and C. Yang, "Research on manufacturers' decision-making to incentive innovation of shared suppliers in a competitive environment," Journal of Systems Engineering, vol. 35, no. 1, pp. 105-119, 2020.

[30] Y. Chen, Y. V. Joshi, J. S. Raju, and Z. J. Zhang, "A theory of combative advertising," Marketing Science, vol. 28, no. 1, pp. 1-19, 2009.

[31] A. A. Tsay and N. Agrawal, "Channel dynamics under price and service competition," Manufacturing \& Service Operations Management, vol. 2, no. 4, pp. 372-391, 2000.

[32] C. A. Ingene and M. E. Parry, Mathematical Models of Distribution Channels, Part of the International Series in Quantitative Marketing Book Series, Springer, Berlin, Germany, 2005.

[33] C. A. Ingene and M. E. Parry, "Bilateral monopoly, identical distributors, and game-theoretic analyses of distribution channels," Journal of the Academy of Marketing Science, vol. 35, no. 4, pp. 586-602, 2007.

[34] B. Liu, G. G. Cai, and A. A. Tsay, "Advertising in asymmetric competing supply chains," Production and Operations Management, vol. 23, no. 11, pp. 1845-1858, 2014. 